ISSN (O) 2589-8779 | (P) 2589-8760

CMRO 04 (02), 806-812 (2021)

ORIGINAL ARTICLE

\title{
Women Health Right and Empowerment during Childbirth
}

\author{
Dr. Norah A. Alshehri MD ${ }^{1}$, Dr. Yasser Sabr MD, MHSc², Alanoud AlAlshaikh ${ }^{3}$, Khalid
} Alshehri ${ }^{4}$, Shahad Alqahtani ${ }^{4}$, Yara Alzamil ${ }^{4}$, Mouaiad Ghabban ${ }^{4}$.

1. King Saud University, Department of Family and Community Medicine, College of Medicine, Riyadh, Saudi Arabia.

2. Department of Obstetrics and Gynecology, College of Medicine, King Saud University, King Saud University Medical City, Riyadh, Saudi Arabia.

3. College of Medicine, King Abdulaziz University, Riyadh, Saudi Arabia.

4. College of Medicine, King Saud University, Riyadh, Saudi Arabia.

Dr. Norah A. Alshehri MD and Dr. Yasser Sabr, MD, MHSc, the first two authors contributed equally to this work.

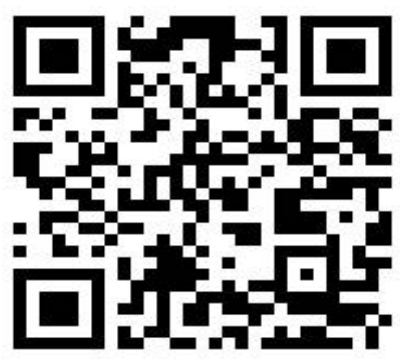

\begin{abstract}
Background: Women health right and empowerment during childbirth is an emerging important topic worldwide. Violation of women dignity, privacy, and confidentiality impact birth outcomes as consequence influencing both morbidity and mortality rate. This occurs as result to complex reasons that attributable to health services which include inadequate coverage of health care, lack of trained assistance, insufficient essential obstetric care and poor health referral system.
\end{abstract}

Objective: To explore women experience during childbirth in terms of health rights and the quality of care provided and to further study women attuited and experience with midwives and their future role in obstetric care.

Method: Based on informant report, a random snowballing sampling technique was carried out through using an anonymous online - based questionnaire. Participants in this study were $(n=360)$ women. Ethical approval was obtained by the institutional review board at King Saud University (IRB No. E-18-32836).

Results: The majority of women reported their childbirth experience as unfavourable. According to our findings, women encounter various kinds of obstetric violence including denial of access to a health care, restriction of analgesia, violation of privacy and failure of obtaining an informed consent which found to be high as (91.0\%), (53.0\%) respectively.

Conclusion: Optimal maternity care can be assured through appropriate access to medical resources and health care expertise with a higher priority committed to supporting midwife - led care during childbirth.

Key words: Childbirth, Obstetric violence, Health right, Midwifes, Saudi Arabia. 


\section{Introduction:}

Childbirth signifies an exceptional experience in a woman's life impacting her both postpartum physical and psychological state. ${ }^{1}$ Studies reporting that $10-34 \%$ of childbirth end with traumatic birth experiences to women. ${ }^{2,3}$

Desirable childbirth outcomes depend on acceptable, affordable and accessible health care system. ${ }^{4}$ However, the medicalization of childbirth experience, and neglect in others context result to abuse. $^{5}$

The literature suggests that mistreatment during childbirth is a worldwide phenomenon, composed of non-supportive care incorporating both physical and verbal abuse, violation of privacy, lack of autonomy to the patient and non-consented procedures. $^{6,7,8}$

A respectful maternity care as envisioned by the World Health Organization (WHO) in

2018 is the care that maintain "dignity, privacy, and confidentiality, ensures freedom from harm and mistreatment, and enables informed choice and continuous support during labour and childbirth". 9

In parallel, a positive childbirth experience can be encouraged through midwife-led care as has been reported by Cochrane reviews. ${ }^{10,} 11$ Such an effective strategy, should promote continuous support for women during childbirth and improve behavior of the caregivers. ${ }^{12,13}$

Women health right and empowerment during childbirth is an emerging important topic. ${ }^{14,15}$ Our study aims to improve maternal health within this context and address this issue to further improve the current health care system and to prevent avoidable adverse events.

\section{Methodology:}

\section{Research Design and Setting}

This cross-sectional study explored women right during childbirth using an anonymous online based questioner posted on Social Media between December 2019 to February 2020.

\section{Subject and Sampling}

A random snowballing sampling technique using an online based questionnaire was carried out.
Participants in this research $(n=360)$ were all primiparous women. Participants were invited to complete an assessment measure based on informant report about their experience during childbirth. Women who were multiparous or had their pregnancy before the year 2016 were excluded from the study.

\section{Research Instrument}

The questionnaire was developed by the authors based on the study objectives. To ensure that it was suitable, precise and relevant, the questionnaire was submitted for evaluation by two obstetricians and a family doctor who provided clinical care for pregnant women. These individuals were acquainted with the survey development.

The questionnaire consisted of 19 items in total.

\section{Statistical analysis}

Categorical variables were presented as frequencies and percentage, while continuous variable was presented as mean and a standard deviations (SD).

\section{Ethical considerations}

The study was approved by the institutional review board at King Saud University (IRB No. E-1832836).

\section{Result:}

Table 1 demonstrate the sociodemographic and clinical characteristics of women whom gave birth. A 360 women, with a mean age of $34.08 \pm 7.35$ years were included. Of these, $94.0 \%$ were Saudi, $62.0 \%$ held a bachelor's degree, and $34.0 \%$ reported an overall monthly household income of more than $10,000 \mathrm{SR}$.

Moreover, 35.0\% of participants reported having their birth in a teaching hospital followed by a privet hospital by $34.0 \%$. In comparison, the husband was reported to be the companion in childbirth by $40.0 \%$, while $39.0 \%$ of respondents reported no companion during childbirth.

Corresponding Author: Dr. Norah A. Alshehri, MD Assistant Professor and Consultant of Family Medicine and Diabetes Department of Family and Community Medicine, College of Medicine King Saud University Email: drnorah19@gmail.com

ORCID identifier is 0000-0002-9775-9501 
Table 1: Distribution of participants by sociodemographic and clinical characteristics $(n=$ 360)

\begin{tabular}{|c|c|c|}
\hline Variable & Frequency & Percentage \\
\hline Age (Mean (SD)) & 34.08 & \pm 7.35 \\
\hline \multicolumn{3}{|l|}{ Nationality } \\
\hline Saudi & 340 & $94.0 \%$ \\
\hline \multirow[t]{2}{*}{ Non-Saudi } & 20 & $6.0 \%$ \\
\hline & 360 & $100.0 \%$ \\
\hline \multicolumn{3}{|c|}{ Marital Status } \\
\hline Married & 329 & $91.0 \%$ \\
\hline \multirow[t]{2}{*}{ Divorce } & 31 & $9.0 \%$ \\
\hline & 360 & $100.0 \%$ \\
\hline \multicolumn{3}{|c|}{ Education } \\
\hline Secondary or less & 37 & $37.0 \%$ \\
\hline Bachelor's degree & 224 & $62.0 \%$ \\
\hline \multirow{2}{*}{ Postgraduate } & 99 & $28.0 \%$ \\
\hline & 360 & $100.0 \%$ \\
\hline \multicolumn{3}{|c|}{ Monthly Household Income in Saudi Riyal (SR) } \\
\hline Less than 5,000 & 47 & $13.0 \%$ \\
\hline 5,000 up to 10,000 & 69 & $19.0 \%$ \\
\hline 10,000 up to 20,000 & 123 & $34.0 \%$ \\
\hline \multirow[t]{2}{*}{ More than 20,000} & 121 & $34.0 \%$ \\
\hline & 360 & $100.0 \%$ \\
\hline \multicolumn{3}{|c|}{ Occupation } \\
\hline Housewife & 114 & $32.0 \%$ \\
\hline Educator & 88 & $24.0 \%$ \\
\hline Health care worker & 96 & $27.0 \%$ \\
\hline \multirow[t]{2}{*}{ Others } & 62 & $17.0 \%$ \\
\hline & 360 & $100.0 \%$ \\
\hline \multicolumn{3}{|c|}{ Companion during childbirth } \\
\hline Husband & 144 & $40.0 \%$ \\
\hline Mother & 67 & $19.0 \%$ \\
\hline Friend & 10 & $3.0 \%$ \\
\hline \multirow[t]{2}{*}{ Non } & 139 & $39.0 \%$ \\
\hline & 360 & $100.0 \%$ \\
\hline \multicolumn{3}{|c|}{ Health care setting } \\
\hline Public hospital & 109 & $30.0 \%$ \\
\hline Privet hospital & 124 & $34.0 \%$ \\
\hline \multirow[t]{2}{*}{ Teaching hospital } & 127 & $35.0 \%$ \\
\hline & 360 & $100.0 \%$ \\
\hline
\end{tabular}

Table 2 represents women health right violation during childbirth. Almost (94.0\%) reported denial of access to a medical care. Moreover, during giving birth, most women described that their needs were not attended by (87.0\%). Restriction of analgesia was a common complaint by women during childbirth as well.

Among variables examined, violation of privacy and failure of obtaining an informed consent were found to be the most common unethical practice $(91.0 \%),(53.0 \%)$ respectively. Around $(64.0 \%)$ of women rated their childbirth experience as unfavorable.

Table 2: Women rights and experience during childbirth $(n=360)$

\begin{tabular}{|c|c|c|}
\hline Variable & Frequency & Percentage \\
\hline Denial of access to a medical care \\
\hline Yes & 22 & $6.0 \%$ \\
\hline No & 338 & $94.0 \%$ \\
\hline \multicolumn{3}{|c|}{ Attending women needs } \\
\hline Yes & 47 & $13.0 \%$ \\
\hline No & 313 & $87.0 \%$ \\
\hline \multicolumn{3}{|c|}{ Pain management } \\
\hline Yes & 44 & $100.0 \%$ \\
\hline No & 316 & $88.0 \%$ \\
\hline Unnecessary birth interventions \\
\hline Yes & 141 & $39.0 \%$ \\
\hline No & 219 & $61.0 \%$ \\
\hline \multicolumn{3}{|c|}{ Violation of privacy } \\
\hline \multicolumn{3}{|c|}{34} \\
\hline Yes & 326 & $9.0 \%$ \\
\hline No & $91.0 \%$ \\
\hline
\end{tabular}

\begin{tabular}{|c|c|c|}
\hline \multicolumn{3}{|c|}{ Informed consent obtained from woman } \\
\hline Yes & 168 & $47.0 \%$ \\
\hline No & 192 & $53.0 \%$ \\
\hline & 360 & $100.0 \%$ \\
\hline \multicolumn{3}{|c|}{ Childbirth experience } \\
\hline Favorable & 130 & $36.0 \%$ \\
\hline Unfavorable & 230 & $64.0 \%$ \\
\hline & 360 & $100.0 \%$ \\
\hline
\end{tabular}


Figure 1 shows the most common unconsented obstetric interventions during childbirth that experienced by women. Around (39.0\%) of women had their birth through a cesarean section. In contrast, women who had vaginal delivery, their birth were complicated by an episiotomy (36\%), while one-fourth needed an induction of labor.

Figure 1: Unconsented obstetric interventions during childbirth

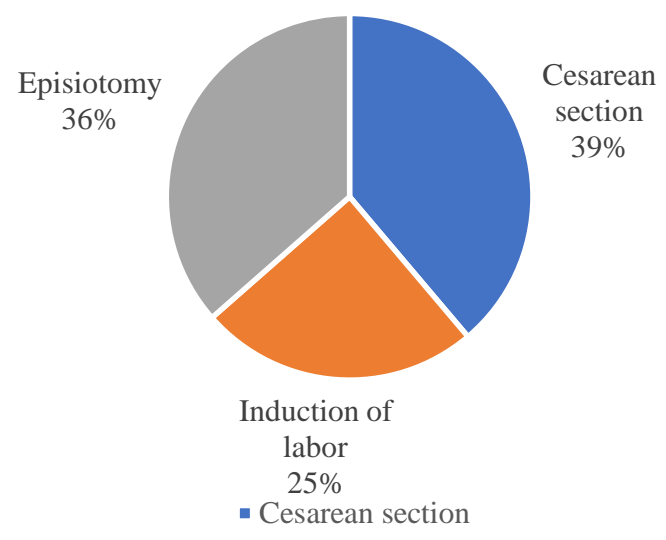

Table 3 shows women experience and attitude towards midwives. Out of 360 women, 174 had in interaction with midwifes. Out of those women, more than half reported their experience as favorable. However, disapproval regarding their future role was noted by $(53.0 \%)$ of all women.

Table 3: Women attitudes and experience with midwives

\begin{tabular}{|c|c|c|}
\hline Variable & Frequency & Percentage \\
\hline \multicolumn{3}{|c|}{ Women experience with midwifes } \\
\hline Favorable & 148 & $85.0 \%$ \\
\hline \multirow[t]{2}{*}{ Unfavorable } & 26 & $15.0 \%$ \\
\hline & 174 & $100.0 \%$ \\
\hline \multicolumn{3}{|c|}{ Midwives could play a role during childbirth } \\
\hline Yes & 170 & $47.0 \%$ \\
\hline \multirow[t]{2}{*}{ No } & 190 & $53.0 \%$ \\
\hline & 360 & $100.0 \%$ \\
\hline \multicolumn{3}{|c|}{$\begin{array}{l}\text { Midwives based-medical care would improve the } \\
\text { quality of childbirth }\end{array}$} \\
\hline Yes & 162 & $45.0 \%$ \\
\hline \multirow[t]{2}{*}{ No } & 198 & $55.0 \%$ \\
\hline & 360 & $100.0 \%$ \\
\hline
\end{tabular}

\section{Discussion:}

Quality of care is an important element of the right to health. ${ }^{16}$ Building on this concept, our study investigated six health care characteristics that would insure both equity and dignity for women during childbirth as describes by the World Health Organization (WHO). ${ }^{17,18}$

An alarming rate was observed in this study among women whom denied an access to a reproductive care service during childbirth. It is found that a range of barriers limit women's access to care, including distance, cost or health facilities reglations. ${ }^{19}$

Ensuring women needs during delivery is a key characteristic in patient centered care that aims to a better quality of maternity care. Most women reported a lack of support with around one third had to endure this experience alone with no companion. A study explained that women experience of mistreatment during childbirth is strongly associated to lack of support; ${ }^{20}$ this could be related to the vulnerability of women in these circumstances.

Women experience painful events during childbirth, to ease her pain, labor analgesia are usually introduced. ${ }^{21}$ However, the majority of women in our sample reported no pain management which is considered as a violation to a fundamental health right. ${ }^{22}$ An explanation to this and by the exclusion of the medical rezoning could be relied to the cost of the procedure.

Compromising women privacy and failure in obtaining an informed consent were noted as well. Such an intimate issue is both ethical and legal. ${ }^{23}$ The law mandate expressing consent as an essential component of care providing accurate, clear and evidence-based information. ${ }^{24}$ In Saudi Arabia, women are legally having the rights to consent for their health care. ${ }^{25}$ In contrast to this study findings, around half the women who were included did not consented; this could be attributed to lack of awareness about their legal right.

Unconsented obstetric interventions during childbirth were common practices in our study sample. It is critical to note that most procedures are done as routine by health professionals. ${ }^{26}$ Evidence 
based approaches should be adapted to address this concern especially in the absence of clinical need.

Supportive care during childbirth is an important factor contributing to women's experiences of delivery. ${ }^{27}$ Similarly, midwifes led care during childbirth among our surveys had a favorable experience. Nevertheless, some showed distrust in their future role in improving maternity care. It could be due less interaction and lack of knowledge about their role in maternity care.

\section{Conclusion and recommendations:}

Women's health and right issues are gaining a global trend. Nationally, according to the Ministry of Health, morbidity and mortality rate among women and children are high. ${ }^{28}$ Reasons that attributable to health services includes inadequate coverage of health care, lack of trained assistance, insufficient essential obstetric care and poor health referral system.

Provision of optimal maternity care will necessitate access to appropriate medical institutions and expert care. This includes ensuring full and unrestricted access to prenatal care, resources and expertise, as well as access to safe, pain-free childbirth and comprehensive medical care before, during and after birth.

Furthermore, a higher priority should be committed to support midwifes led care during childbirth. Having skilled midwives in antenatal, natal, or postnatal is one of key potential interventions for reducing maternal and prenatal mortality. Consequently, it goes in alliance with the united nation sustainable development goals in decreasing the neglect of the rights, health and equality of women in the country.

\section{Conflict of interest:}

Authors have no interest to disclose. This manuscript has not been published and is not under consideration for publication elsewhere.

Affiliation : This work was supported by King Saud University and College of Medicine Research Center, Deanship of Scientific Research, King Saud University, Riyadh, Saudi Arabia.

\section{Declaration of Funding}

This research was fully financially independent and funded by the researchers.

\section{Declaration of Financial}

This research was fully financially independent and funded by the researchers.

\section{Author Contributions}

The single authors was contributed equally in Conceptualization, Methodology, Software, Data curation, Writing- Original draft preparation, Visualization, Investigation, Supervision, Validation, Writing- Reviewing and Editing.

\section{Acknowledgments}

The author thanks the Deanship of Scientific Research and RSSU at King Saud University for their technical support.

This work was supported by the College of Medicine Research Center, Deanship of Scientific Research, King Saud University, Riyadh, Saudi Arabia.

\section{References:}

1. Bell A, Andersson E. The birth experience and women's postnatal depression: A systematic review. Midwifery. 2016; 39:112-123.

2. Soet J, Brack G, DiIorio C. Prevalence and Predictors of Women's Experience of Psychological Trauma During Childbirth. Birth. 2003;30(1):36-46.

3. AYERS S. Delivery as a Traumatic Event: Prevalence, Risk Factors, and Treatment for Postnatal Posttraumatic Stress Disorder. Clinical Obstetrics and Gynecology. 2004;47(3):552-567.

4. Tunçalp Ö, Were W, MacLennan C, Oladapo O, Gülmezoglu A, Bahl R et al. Quality of care for pregnant women and newborns-the WHO vision. BJOG: An International Journal of Obstetrics \& Gynaecology. 2015;122(8):1045-1049.

5. Miller S, Abalos E, Chamillard M, Ciapponi A, Colaci D, Comandé D et al. Beyond too little, too late and too much, too soon: a pathway towards evidence- 
based, respectful maternity care worldwide. The Lancet. 2016; 388(10056):2176-2192.

6. Bohren M, Vogel J, Hunter E, Lutsiv O, Makh S, Souza J et al. The Mistreatment of Women during Childbirth in Health Facilities Globally: A Mixed-Methods Systematic Review. PLOS Medicine. 2015;12(6):e1001847.

7. Hulton L, Matthews Z, Stones R. Applying a framework for assessing the quality of maternal health services in urban India. Social Science \& Medicine. 2007; 64(10):2083-2095.

8. Noble A. Birth Crisis Birth Crisis Sheila Kitzinger ISBN: Taylor \& Francis. British Journal of Midwifery. 2007;15(4):239239.

9. Yildız H. Intrapartum Care Model For A Positive Childbirth Experience: World Health Organization' Recommendations. Kocaeli Üniversitesi Sağlık Bilimleri Dergisi. 2019;:39-44.

10. HODNETT E. Pain and women's satisfaction with the experience of childbirth: A systematic review. American Journal of Obstetrics and Gynecology. 2002; 186(5):S160-S172.

11. Sandall J, Soltani H, Gates S, Shennan A, Devane D. Midwife-led continuity models versus other models of care for childbearing women. Cochrane Database of Systematic Reviews. 2016;

12. Hodnett E, Gates S, Hofmeyr G, Sakala C. Continuous Support for Women During Childbirth. Birth. 2008;32(1):72-72.

13. Madden K, Middleton P, Cyna A, Matthewson M, Jones L. Hypnosis for pain management during labour and childbirth. Cochrane Database of Systematic Reviews. 2016;.

14. World Health Organization. Standards for improving quality of maternal and newborn care in health facilities. World Health Organization. [Internet]. Who.int. 2020 [cited 6 September 2020]. Available from: https://www.who.int/docs/default-source/mcadocuments/advisory-groups/quality-of-care/standards- for-improving-quality-of-maternal-and-newborn-carein-health-facilities.pdf?sfvrsn $=3 \mathrm{~b} 364 \mathrm{~d} 8 \_2$

15. Kinney M, Boldosser-Boesch A, McCallon B. Quality, equity, and dignity for women and babies. The Lancet. 2016;388(10056):2066-2068.

16. Independent Expert Review Group (iERG). The second report of the independent expert review group (iERG) in information and accountability for women's and children's health [Internet]. Who.int. 2020 [cited 6 September 2020]. Available from:

https://www.who.int/woman child accountability/ierg/reports/ 2013/en/

17. Crossing the Quality Chasm: A New Health System for the 21st Century. Journal For Healthcare Quality. 2002; 24(5):52.

18. Lamb-White J. World Health Organization. International Journal of Health Care Quality Assurance. 2005;18(7).

19. World Health Day 1998: Address Unsafe Abortion [Internet]. Who.int. 2020 [cited 6 September 2020]. Available from: https://www.who.int/docstore/world-healthday/en/pages1998/whd98 10.html

20. Bohren M, Hunter E, Munthe-Kaas H, Souza J, Vogel J, Gülmezoglu A. Facilitators and barriers to facility-based delivery in low- and middle-income countries: a qualitative evidence synthesis. Reproductive Health. 2014;11(1).

21. Schrock S, Harraway-Smith C. Labor Analgesia [Internet]. Aafp.org. 2020 [cited 6 September 2020]. Available from: https://www.aafp.org/afp/2012/0301/p447.html

22. WHO recommendation on epidural analgesia for pain relief during labour | RHL [Internet]. Extranet.who.int. 2020 [cited 6 September 2020]. Available from: https://extranet.who.int/rhl/topics/preconceptionpregnancy-childbirth-and-postpartum-care/care-duringchildbirth/care-during-labour-1st-stage/whorecommendation-epidural-analgesia-pain-relief-duringlabour

23. Reed R, Sharman R, Inglis C. Women's descriptions of childbirth trauma relating to care provider actions and interactions. 
BMC Pregnancy and Childbirth. 2017;17(1).

24. Golden P, Coercion or consent? British Journal of Midwifery, 2018; 26(7)

https://doi-

org.ezproxy.uws.edu.au/10.12968/bjom.2018.26.7.482

25. Al-Amoudi S. Health empowerment and health rights in Saudi Arabia. Saudi Medical Journal. 2017;38(8):785-787.

26. Sadler M, Santos M, Ruiz-Berdún D, Rojas G, Skoko E, Gillen P et al. Moving beyond disrespect and abuse: addressing the structural dimensions of obstetric violence. Reproductive Health Matters. 2016;24(47):47-55.

27. HODNETT E. Pain and women's satisfaction with the experience of childbirth: A systematic review. American Journal of Obstetrics and Gynecology. 2002;186(5):S160-S172.

28. [Internet]. Scfhs.org.sa. 2020 [cited 8 September 2020]. Available from: https://www.scfhs.org.sa/en/MESPS/TrainingProgs/Trai ningProgsStatement/Midwifery/Documents/Program $\% 2$ 0Booklit.pdf

How to cite this article: Alshehri, N. A., Sabr, Y., AlAlshaikh, A., Alshehri, K., Alqahtani, S., Alzamil, Y., \& Ghabban, M. (2021). Women Health Right and Empowerment during Childbirth. Journal of Current Medical Research and Opinion, 4(02). https://doi.org/10.15520/jcmro.v4i02.394 